\title{
Reply to Oliver W Quarrell et al.: "Letter in response to Tibben et al., Risk Assessment for Huntington's Disease for (Future) Offspring Requires Offering Preconceptional CAG Analysis to Both Partners"
}

\author{
Aad Tibben ${ }^{\mathrm{a}, *}$, Wybo J. Dondorp ${ }^{\mathrm{b}}$, Guido M. de Wert ${ }^{\mathrm{b}}$, Christine E. de Die-Smulders ${ }^{\mathrm{c}}$, \\ Moniek Losekoot ${ }^{\mathrm{a}}$ and Emilia K. Bijlsma ${ }^{\mathrm{a}}$ \\ ${ }^{a}$ Department of Clinical Genetics, Leiden University Medical Center, Leiden, The Netherlands \\ ${ }^{\mathrm{b}}$ Department of Health, Ethics and Society, Maastricht University, Maastricht, The Netherlands \\ ${ }^{\mathrm{c}}$ Department of Clinical Genetics, Maastricht University Medical Centre, Maastricht, The Netherlands
}

\section{Dear Editor,}

We are grateful to Quarell and others for their response [1] to our article [2], and for the opportunity to respond. The authors feel that the case for altering the current guidelines for predictive testing for Huntington's disease [3] has not yet been made because of insufficient information about the behaviour of intermediate alleles (IA), reduced penetrance alleles (RPA), and fully penetrant alleles (FPA) in families not yet identified as Huntington families. We agree with the authors that more knowledge of and insight into the dynamics of the alleles is needed to justify changing the guidelines. However, we want to meet the concerns of couples who wish to have offspring but feel the responsibility for preventing the conception or birth of a child with an HD allele. One of the main reasons of individuals at risk to request predic-

\footnotetext{
*Correspondence to: Aad Tibben, PhD, Leiden University Medical Center, Department of Clinical Genetics, P.O Box 9600, 2300 RC Leiden, The Netherlands. Tel.: +31 71526 8033; Fax: +31 71526 6794; E-mail: a.tibben@lumc.nl.
}

tive testing is the wish to have children. Until now, tested individuals expect that either test result allows them to exclude HD in their offspring, in case of a unfavourable test result by opting for prenatal (PND) or preimplantation genetic testing (PGT). The aim of genetic counseling, in general [4] and according to the guidelines [3], is to give individuals at risk, who wish to take the predictive test, up to date, relevant information in order to make an informed voluntary decision. Moreover, couples opting for prenatal testing should be made fully aware of all possible outcomes and consequences of prenatal testing [3].

The question of an identified non-carrier, whether the chance of Huntington in his or her offspring is excluded, cannot be confirmed because of the - albeit very small - chance of an expanded repeat in the nonHD partner. Similarly, a carrier and his or her partner, opting for PND or PGT, need to be informed that prenatal testing might reveal a small chance that an expanded repeat will be found in the non-HD partner. Consequently, couples deserve to be well informed and counseled so that they can make a decision that does justice to their reproductive concerns. 
The authors compare our case with chromosome microarray analyses in the context of PND that might elicit some copy number variants that may predispose to developmental disability or neuropsychiatric illness. Moreover, their comparison with expanded carrier screening for cystic fibrosis, spinal muscular atrophy or fragile X concerns decisions in the context of population screening, which makes this analogy invalid.

Quarell c.s. seem to assume that we propose to routinely test the non-HD partners - which they would not prefer. We definitely agree on the latter as routine testing is not our point. We argue that this test should be an option in counseling couples in this specific situation. We acknowledge the concerns and uncertainties surrounding this additional testing, but that is no reason not to discuss this testing opportunity with couples who might want to use it because of their specific request for help, c.q. prevention of Huntington's disease in offspring. Whether counseling is offered from a non-directive counseling model or a shared decision-making model, in our opinion couples need to be fully informed. But given the uncertainties and complexities of the alleles in question, we do think that discussing and possibly offering an additional test for non-HD partners should take place in a research setting to investigate what sound counseling entails in this context.

Aad Tibben, $\mathrm{PhD}$

Wybo J. Dondorp, PhD

Guido M. de Wert, $\mathrm{PhD}$

Christine E. de Die-Smulders, MD, PhD

Moniek Losekoot, PhD

Emilia K. Bijlsma MD, PhD

\section{REFERENCES}

[1] Quarrell O, Delatycki MB, Clarke A, et al. Letter in response to Tibben et al Risk assessment for Huntington's Disease for (future) offspring requires offering preconceptual CAG analysis to both partners. J Huntingtons Dis. 2019.

[2] Tibben A, Dondorp WJ, de Wert GM, de Die-Smulders CE, Losekoot M, Bijlsma EK. Risk Assessment for Huntington's Disease for (Future) Offspring Requires Offering Preconceptional CAG Analysis to Both Partners. J Huntingtons Dis. 2019;8(1):71-8.

[3] MacLeod R, Tibben A, Frontali M, et al. Recommendations for the predictive genetic test in Huntington's disease. Clin Genet. 2013;83(3):221-31.

[4] Fraser FC. Genetic counseling. Am J Hum Genet. 1974; 26(5):636-59. 